\title{
Modelling of a Heated Gas-solid Fluidised Bed using Eulerian Based Models
}

\author{
A. Potgieter ${ }^{a}$, M. Bhamjee ${ }^{b}$, S. Kruger ${ }^{c}$ \\ Received 22 February 2021, in revised form 9 May 2021 and accepted 13 August 2021
}

\begin{abstract}
An Eulerian-Eulerian granular model was used to simulate the flow and heat transfer through a heated gassolid fluidised bed. The primary objective of the study was to determine whether the Eulerian-Eulerian granular model adequately predicts the chamber pressure drop, temperature, and bed expansion through the bed. The model predictions were assessed and validated for various flow-regimes, namely the fixed-bed, smooth, bubbling fluidisation, and the maximum fluidisation regimes. This was done on an experimental scale heated gas-solid fluidised bed. However, the results are generalisable for heated gas-solid fluidised beds when the flow is laminar. Numerical models were created using Computational Fluid Dynamics (CFD). The CFD-model predictions were investigated, analysed, and compared to experimental results. Basic experiments were carried out to obtain varying hydrodynamic characteristics. The results showed a slight overprediction of pressure drop and bed expansion, however, the results were still in close agreement with the experiment. In contrast, underprediction of chamber temperatures were obtained. Based on the results of this study, it is recommended that the Eulerian model be used to predict dynamic flow behaviour. Before minimum fluidisation, when in a fixed bed regime, pressure drop in the chamber increases with no increase in bed height. No visible bubbles were present in the fixed bed regime. When fluidisation has been reached, the bed height rises whereas the pressure drop tends to a constant value. Bubble size increases with chamber height and increased superficial velocities. Bubble speed increased with increased chamber height. With increased superficial velocity, the chamber temperatures increase to a maximum temperature of 326.65 $K$ with an initial heating element temperature of $373.15 \mathrm{~K}$. However, when excessive heat is present in the gas-solid fluidised bed, other methods that sufficiently incorporate particle-particle interactions and bubble-bubble interactions, are recommended. An investigation should be lent to bubble-bubble interactions in the fluidised beds with relation to heat transfer.
\end{abstract}

Additional keywords: Heated fluidised bed, computational fluid dynamics, CFD, Eulerian, granular, fluidisation, gas-solid

a. Department of Mechanical Engineering Science, Faculty of Engineering and the Built Environment, University of Johannesburg, South Africa.

b. Department of Mechanical Engineering Science, Faculty of Engineering and the Built Environment, University of Johannesburg, South Africa. E-mail: muaazb@uj.ac.za

c. Department of Mechanical Engineering Science, Faculty of Engineering and the Built Environment, University of Johannesburg, South Africa.

\section{Nomenclature}

\section{Roman}

A Cross sectional area, $\mathrm{m} 2$

$C_{D} \quad$ Drag coefficient

$C_{P} \quad$ Specific heat, $\mathrm{J} / \mathrm{kg} \mathrm{mol}$

$d_{P} \quad$ Particle diameter, $\mathrm{m}$

$e_{S S} \quad$ Coefficient of restitution

E Total Energy, J

$f$ Discrete solutions, $\mathrm{Pa}$ for Pressure, $\mathrm{K}$ for Temperature

$f_{h=0} \quad$ Richardson extrapolation

$F \quad$ Forces, $\mathrm{N}$

$g_{0, k l} \quad$ Radial distribution

$g_{0, s s} \quad$ Radial distribution coefficient

$G C I[i]$ GCI estimated fractional error; $i=$ fine, coarse or $i=1,2,3$ (diff mesh sizes)

h Heat transfer coefficient, $\mathrm{W} / \mathrm{m}^{2} \cdot \mathrm{s} \cdot \mathrm{K}$

$h_{1} \quad$ Coarse grid

$h_{2} \quad$ Fine grid

$h_{p q} \quad$ Heat transfer coefficient, $\mathrm{J} / \mathrm{m} 2 \cdot \mathrm{s} \cdot \mathrm{K}$

$I_{2 D} \quad$ Inertia, $\mathrm{kg} / \mathrm{m}^{2}$

J Diffusive flux, $\mathrm{kg} / \mathrm{m}^{2} \cdot \mathrm{s}$

$K_{p g} \quad$ Fluid-solid exchange coefficient, $\mathrm{kg} / \mathrm{m} \cdot \mathrm{s}$

$k_{\vartheta_{s}} \quad$ Diffusion coefficient, $\mathrm{m}^{2} / \mathrm{s}$

$L \quad$ Granular bed height, $\mathrm{m}$

$m \quad$ Mass, $\mathrm{kg}$

$\dot{m} \quad$ Mass flow rate, $\mathrm{kg} / \mathrm{s}$

$N u_{s} \quad$ Relative Nusselt number

$p \quad$ Static pressure, $\mathrm{Pa}$

$\Delta P \quad$ Pressure drop, $\mathrm{Pa}$

$P \quad$ Pressure, $\mathrm{Pa}$

$p_{\text {friction }}$ Pressure (friction, particle, gas), $\mathrm{Pa}$

$\mathrm{Pr} \quad$ Prandtl number

$Q_{p q} \quad$ Heat exchange coefficient, $\mathrm{W}(\mathrm{J} / \mathrm{s})$

$R e_{s} \quad$ Relative Reynolds number

$r \quad$ Grid refinement ratio

$S_{h} \quad$ Momentum source term

$t \quad$ Time, $\mathrm{s}$

T Temperature, $\mathrm{K}$

$\vec{v} \quad$ Velocity vector, $\mathrm{m} / \mathrm{s}$

$v \quad$ Kinematic viscosity, $\mathrm{m}^{2} / \mathrm{s}$

\section{Greek}

$\alpha_{i} \quad$ Volume fraction $i=\mathrm{p}, \mathrm{g}$

$\gamma \quad$ Granular bulb viscosity, $\mathrm{kg} / \mathrm{m} \cdot \mathrm{s}$

$\gamma_{\vartheta_{p}} \quad$ Collisional dissipation of energy

$\varepsilon \quad$ Voidage

$\eta \quad$ Drag modification factor

$\kappa_{q} \quad$ Thermal conductivity of gas, $\mathrm{W} / \mathrm{mK}$

$\mu \quad$ Dynamic Viscosity, $\mathrm{m}^{2} / \mathrm{s} \mathrm{Pa} \cdot \mathrm{s}$

$\mu_{p, f r} \quad$ Frictional viscosity of the particles, $\mathrm{kg} / \mathrm{ms}$

http://www.saimeche.org.za (open access) (C) SAIMechE All rights reserved. 
$v_{b} \quad$ Airflow through bed

$\rho \quad$ Density, $\mathrm{kg} / \mathrm{m}^{3}$

$\tau \quad$ Shear, $\mathrm{Pa}$

$\beta_{B} \quad$ Fluid-particle friction coefficient, $\mathrm{kg} / \mathrm{m}^{3} \cdot \mathrm{s}$

$\vartheta_{i} \quad$ Granular temperature where $i=\mathrm{p}, \mathrm{g}, \mathrm{K}$

$\begin{array}{ll}\text { Subscripts } \\ g & \text { Gas } \\ p & \text { Particles } \\ s f & \text { Superficial } \\ \varphi_{g p} & \text { Energy exchange between the gas and particle phase } \\ q & \mathrm{q}^{\text {th }} \text { phase }\end{array}$

\section{Introduction}

Gas-solid fluidised beds are commonly used in applications such as fluid bed dryers which, in turn, are extensively applied in the chemical, pharmaceutical, food, dairy and the dyes industries [1,2]. Gas is introduced into the system with a velocity that imposes a high enough drag to overcome the downwards force of gravity [2]. Particles are separated from each other as they are partially suspended in the stream of the gas, causing the gas to behave in a fluid-like manner known as fluidisation [3]. During this state, the particles' exposed surface area increases. Surrounded by injected air, the particles dry out more effectively [4].

When the fluidised bed is exposed to low gas flow rates, the buoyancy force and surface tension govern the flow of the bubbles [5]. This phase occurs before minimum fluidisation is reached and is known as the fixed bed regime. It has no significant change in the fluidisation conditions as the velocity of the gas is too low to suspend particles [6]. Increasing the flow rate past that of the homogeneous fluidisation stage (minimum fluidisation) causes large instabilities resulting in bubble growth [6]. As the bubbles expand into a lower pressured section of the bed, they increase in size and move faster upwards with increased buoyancy [2,7]. Collisions with other bubbles are more frequent with these larger bubbles [6]. When ascending bubbles coalesce with each other, they create larger bubbles which results in an increased buoyancy force and a reduced drag force resulting in an upward acceleration and consequently an increase in velocity [6]. These bubble size changes affect the interfacial surface through which mass and heat transfer occur [8]. It should be noted that this is the case whereby the gas-flow is opposite to the gravitational axis

Pressure drop is also influenced by drag, fluid velocity, and flow rates, leading to it being a critical design parameter for fluidisation in fluidised beds [9]. Drag forces create a pressure drop across the bed [10] that opposes the gravitational force of the particles [11]. Minimum fluidisation occurs when this pressure drop sufficiently supports the weight of the particles [12]. Minimum fluidisation velocity characterises the hydrodynamics of the material behaviour inside a fluidised bed and can directly be linked to the bed height and flow conditions [6].

Temperature control in fluidised beds promotes the transport process of heat and mass transfer $[3,13]$. Whilst mass-transfer does not take place in a non-reacting heated fluidised bed i.e., when chemical reactions are not present, it is important to account for mass transfer in reacting fluidised beds i.e. when chemical reactions are present [14]. Heat transfer is especially important to ensure minimal energy consumption [13]. Certain temperatures need to be maintained [6] to ensure a particular application is met (such as drying) [13]. Heat transfer takes place through conduction (particle-to-particle; particle-to-wall interactions), convection (gas-to-particle; gas-to-wall), and radiation (particle-to-gas; wall-to-gas) [15]. Radiation only becomes significant at high-temperature operations [2]. The fluidised beds have good fluidisation mixing characteristics due to moving particles that transport both mass and heat efficiently as the contact surface area between gas and particles increases $[15,16]$.

Bed expansion and voidage are closely related. The voidage, in a granular system, is the fraction of the total volume or space between the solids within which fluid can flow [17]. The increase of bubbles results in the rise of the overall bed, which creates a bed expansion [4]. The bed expansion correlates with the voidage. The voidage can also have an impact on the drag law that is used throughout the equations of momentum and continuity with an added drag force correlation [18].

Traditional CFD applications consist of two distinct approaches that form the basis for all derived methods. The Lagrangian method focuses on particle-particle collisions and forces that act on a specific particle [18]. Conversely, the Eulerian method focuses on fully interpenetrating continua and the application of both the continuity and momentum equations [19]. Both methods conform to solving the continuity and momentum equations known as the Navier Stokes (NS) equations [19]. The Eulerian method is based on the Control Volume approach, whereas the Lagrangian method is based on a Control Surface approach [19]. The Lagrangian method assumes that the starting position is known and treats the subsequent position as the dependent variable. In contrast, in the Eulerian method, a fixed position is required as the independent variable, with an initial desired position [20]. The Eulerian-method is one of the most widely used models because it results in a lower computational cost and simulation time for most cases [8,21].

Many studies simplify multiphase-systems represented by the EE-model, to a two-dimensional (2D) model $[18,22,23,24]$ with uniformly spherical particles $[8,23,25]$. 2D-models are easy to perform and develop quicker simulations [26], but with the disadvantage that they do not necessarily capture the proper physics [23]. Both overprediction and underprediction can occur in 2D-models $[8,26]$. Incorrect empirical constants and closures could also lead to overprediction or underprediction [8]. Variations in time-steps were observed in ranges $0,001 \mathrm{~s}$ to $0,0001 \mathrm{~s}$ $[22,27,28,29,30]$. Various studies show that the conductive heat transfer is more dominant in non-cohesive particles $[31,32,33]$, which led to the disregard of conduction heat transfer and radiation in the CFD-model setup. Parameters such as temperature, velocity and flow rate account for heat and mass transfer [1]. Pressure drop and temperature variations create some of the main effects of hydrodynamics and transport processes inside a fluidised bed. Apart from mathematics, multiphase flow modelling can be affected by the mesh, type of modelling approach, time-step between calculations, convergence, initial assumptions, and boundary conditions [34]. Each model needs to show a certain degree 
of validity through these areas of influence, and the model needs to be verified by experimental results to ensure the validity of the application [35].

The Eulerian-model consists of a reasonably realistic approach to scale-up studies of industrial-scale fluidised bed systems [36]. Research on Eulerian-models assists in bridging the gaps between predictions with current methods and ways to improve future methods. To understand the role of mass and heat transfer in the efficiency of fluidised beds, it is essential to consider the critical variables of pressure drop, temperature, bed height, superficial velocity, flow rate, and minimum fluidisation velocity. Whilst there is a body of research that has studied the use of Eulerian-Eulerian granular models or Eulerian models coupled with the discrete element method (DEM) for such applications, such studies $[37,38,39,40,41,42]$ typically focused on the temperature and voidage in the bed. Thus, this paper aimed at filling the gap in literature on the use of such a model to:

1. Predict the temperature as well as the bed height and pressure drop.

2. Assess the predictions when the interphase heat transfer is included via the commonly used Gunn correlation.

3. Assess the model predictions under various flowregimes, namely the fixed-bed, smooth, bubbling fluidisation, and the maximum fluidisation regimes.

This study aimed at investigating, analysing, and comparing predicted Eulerian-model results to experimental data. Basic experiments were carried out to obtain maximum hydrodynamic characteristics. Eulerian-methods were investigated to obtain correlations to pressure drop, temperature and bed expansion behaviours in a gas-solid fluidised bed. The gas-solid fluidised bed contained Geldart group B particles and were exposed to laminar flow. A fixedbed region and bubbling region were observed. Experiments were taken to understand the dynamic behaviour of the different flow regimes, as well as to act as a form of validation against the CFD-model.

\section{Experimental Set-up and Observations from Experiment}

\subsection{Experimental set-up}

Experimental results were used to investigate the validity of the CFD-model. Some of the main observations from the experiments are discussed.

During these experiments, a Fluidisation and Fluid Heat Transfer Unit H692 was used. The chamber was filled with Fused Alumina (Aluminium Oxide) particles. Two probes were inserted, a pressure probe and a temperature probe. The set-up used for the experiment is visually presented in figure 1. A distributor is located at the bottom of the chamber. The probes were adjusted to specific heights to both sides of the heating element such as in figure 2 . A voltage and current controller were used when additional heat was introduced in the chamber through a temperature fluctuation output of the heating element with a temperature of $373.15 \mathrm{~K}$. Table 1 gives a summary of the initial conditions and properties of the heating element, gas and particles. Table 2 provides a summary of the particle properties.

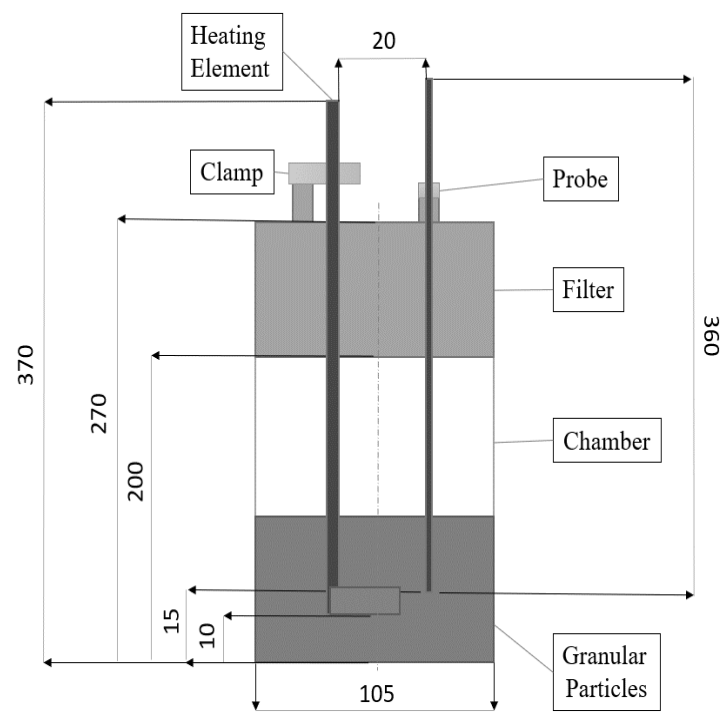

Figure 1 Experimental set-up [36]

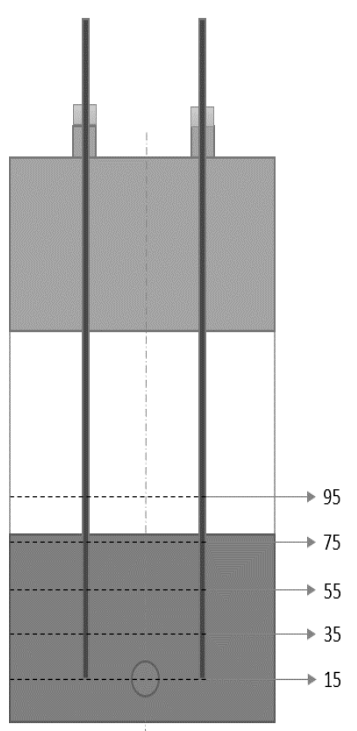

Figure 2 Experimental probe height [36]

Table 1 Heating element, gas, and particle properties [36]

\begin{tabular}{cllcllcccc}
\hline Properties & Values & Units & Properties & Values & Units & Properties & Values & Units \\
\hline Heat element & \multicolumn{3}{c}{ Gas properties } & & \multicolumn{3}{c}{ Particles properties } \\
\hline$\rho$ & 8978 & $\mathrm{~kg} / \mathrm{m}^{3}$ & $P$ & 101.3 & $\mathrm{kNm}$ & $m_{p}$ & 1.3 & $\mathrm{~kg}$ \\
$C_{P}$ & 381 & $\mathrm{~J} / \mathrm{kg} \mathrm{mol}$ & $\rho_{g}$ & 1.204 & $\mathrm{~kg} / \mathrm{m}^{3}$ & $d_{p}$ & 177 & $\mu \mathrm{m}$ \\
$k$ & 387.6 & $\mathrm{~W} / \mathrm{mK}$ & $v$ & $1.326 \times 10^{-5}$ & $\mathrm{~m}^{2} / \mathrm{s}$ & $\rho_{p}$ & 3770 & $\mathrm{~kg} / \mathrm{m}^{3}$ \\
& & & $\mu$ & $1.597 \times 10^{-5}$ & $\mathrm{~m}^{2} / \mathrm{s}$ & $L$ & 70 & $\mathrm{~mm}$ \\
\hline
\end{tabular}

http://www.saimeche.org.za (open access) (C) SAIMechE All rights reserved. 
Table 2 Particle properties [36]

\begin{tabular}{cc}
\hline Particle property & Fused Alumina (white Aluminium Oxide) particles \\
\hline Particle type & Geldart B particles \\
Particle mass $(\mathrm{kg})$ & 1.3 \\
Mean particle diameter $(\mu \mathrm{m})$ & 177 \\
The density of the solid particle $\left(\mathrm{kg} / \mathrm{m}^{3}\right)$ & 3770 \\
Average particle size range $(\mu \mathrm{m})$ & 125 to 350 \\
Grit size & 80 \\
Minimum particle size $(\mu \mathrm{m})$ & 125 \\
Maximum particle size $(\mu \mathrm{m})$ & 274 \\
Granular material bed height & 70 (tapped) up to 85 (untapped) \\
Pour density approximation $\left(\mathrm{kg} / \mathrm{m}^{3}\right)$ & 1620 \\
Shape Factor & 0.73 \\
Initial Packing & Poured (not vibrated) \\
\hline
\end{tabular}

\subsection{Experimental Tests}

Two experiments were conducted during this study. In Experiment 1, readings were taken at specific positions in the fluidised bed by varying the airflow rate through the chamber. The flow rate was varied between $0.4 \mathrm{~L} / \mathrm{s}$ and $1.7 \mathrm{~L} / \mathrm{s}$ with a $0.1 \mathrm{~L} / \mathrm{s}$ interval. The experiment aimed to analyse the minimum fluidisation velocity, pressure drop, bed heights and temperature differences at a specific location. The two probes were kept at the same height as the heating element, near the bottom of the chamber.

In Experiment 2, readings were taken at two constant flow rates with varying probe heights. During the execution of the experiment, the probes were shifted vertically upwards at increasing increments of $20 \mathrm{~mm}$. The initial measurements were taken at $15 \mathrm{~mm}$ from the lower end of the chamber. The experiment aimed to analyse how fluid behaviour differed through the bed and included an investigation of pressure drop and temperatures.

Both experimental procedures distinguish between decreasing flow rates and increasing flow rates. Experimental tests also distinguish between tests with no additional heat and experiments with additional heating. The final distinction was made between a tapped and untapped case, where a tapped case consisted of tapping on the chamber with the knuckles. This tapping compressed the particles to the desired bed height. The compression related to voidage in the fluidised bed.

\subsection{Increasing versus Decreasing Initial Flow Rate}

The most significant differences between increasing and decreasing cases were obtained before minimum fluidisation, where increasing cases showed a higher pressure drop. This difference can be observed in figure 3. Increasing cases further proved higher pressure drops as the airflow had to overcome the initial surface tension of the particle bed when the flow increased. This led to a drag force exerted onto the granular particle, creating a sudden dip in the increased case as the superficial velocity was increased. After minimum fluidisation was reached, the pressure drop converged to similar values for increasing and decreasing cases. This proved that both increasing and decreasing flow rates could be used when the bed is completely fluidised.

The difference between tapped and untapped conditions lies within the compaction of the particles by quantifying the volume of air trapped between them. With increasing cases, the flow must overcome the initial surface tension. With decreasing cases, the flow was already in motion and resulted in a resting phase. Reducing flow rates resulted in a higher particle bed level. This is due to the increasing cases frequently compacting the particles further because of gravitational forces over extended periods.

\subsection{Influence of Additional Heating}

Before minimum fluidisation, a higher-pressure drop was measured for the heated case. This can be observed in figure 4. The heated case caused the untapped conditions of bed height to fluctuate more. Additional heating influenced the rate at which minimum fluidisation was reached. A heated case resulted in a minimum fluidisation velocity sooner than a case with no additional heat. This resulted in shorter periods for a heated flow to be completely fluidised compared to a fluidised bed with no additional heat. For the untapped conditions, nearly no difference was measured between a noheating and heating case after minimum fluidisation. As for the tapped case, a higher-pressure drop was recorded than was the case for no additional heat. When averaging both increasing and decreasing flow rates together, heating cases showed a slightly lower overall pressure drop.

For an untapped condition with no additional heating, higher bed heights were obtained after minimum fluidisation compared to an untapped condition with additional heating. In contrast, tapped conditions with no additional heating resulted in a lower bed height compared to tapped conditions with additional heating. The tapped particles' bed level for heating conditions proved to increase less in overall height, whereas for all other conditions the particles' bed level rapidly increased at minimum fluidisation, after which it increased less prominently. Therefore, no clear trend could be measured between noheating and heating cases, although a clear difference was noticeable.

http://www.saimeche.org.za (open access) (C) SAIMechE All rights reserved. 


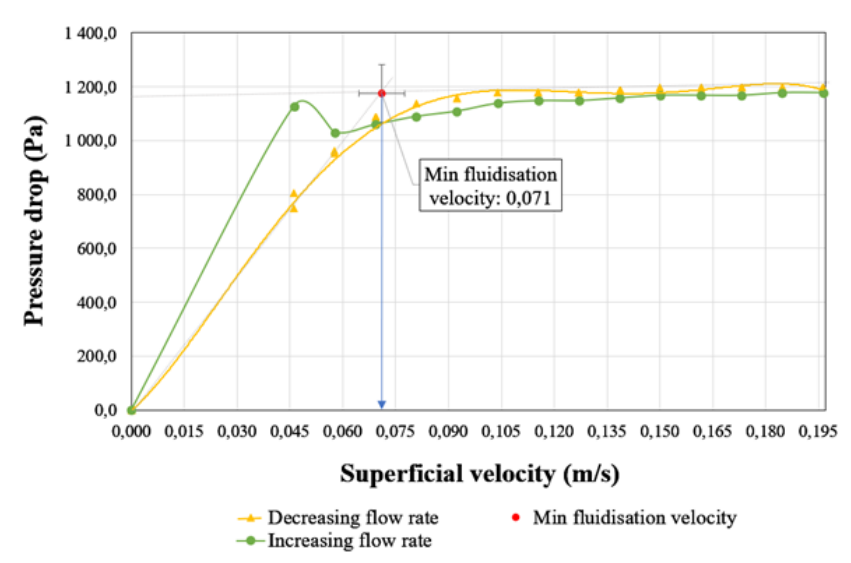

Figure 3 Pressure drop versus superficial velocity, under increasing and decreasing flow rates for heating, tapped conditions to determine the minimum fluidisation velocity

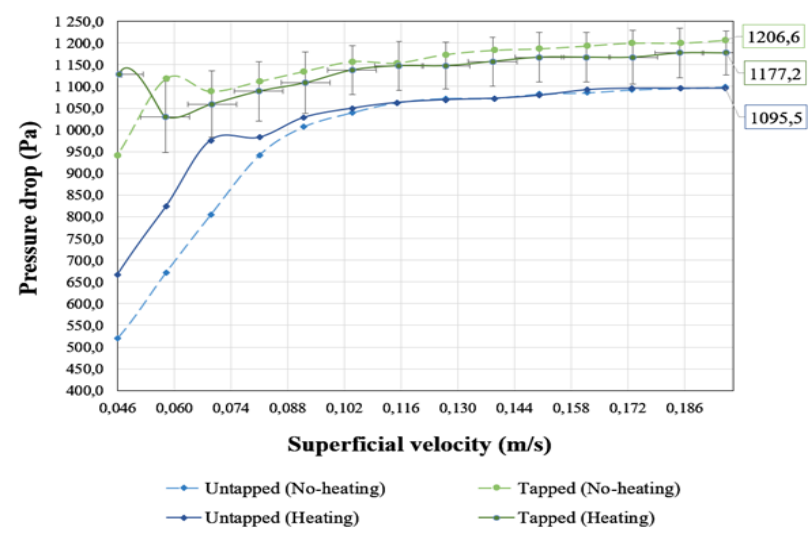

Figure 4 Pressure drop versus superficial velocity, under increasing flow rates for heating, no-heating, tapped, and untapped conditions

\subsection{Tapped versus Untapped Initial Conditions}

A tapped case relates to when the knuckles are used to tap on the bed chamber's glass outer shell lowering the bed level to $0.6 \mathrm{~m}$ compared to an untapped bed level of $0.7 \mathrm{~m}$. A difference was observed between a tapped and untapped condition where a tapped condition showed a higher pressure drop for all superficial velocities (typically around $100 \mathrm{~Pa}$ difference at maximum pressure drop). For the pressure drop across the bed in the vertical direction, the pressure drop proved relatively the same at lower probe heights (closer to the bottom- densest packed areas), whereas, at a height of $35 \mathrm{~mm}$, the untapped condition experienced lower pressure drops than the tapped conditions. Approximately, a $50 \mathrm{~Pa}$ difference was observed between tapped and untapped conditions over the probe height [36].

Similar temperatures were obtained in a stable state (after $0.115 \mathrm{~m} / \mathrm{s}$ ) for both conditions whereas, at superficial velocities below minimum fluidisation velocity, the untapped temperature showed a $4.00 \mathrm{~K}$ higher difference. All other temperatures had fluctuated differences between a $1.00 \mathrm{~K}$ to $3.00 \mathrm{~K}$ pertaining to the superficial velocities. Nevertheless, by comparing temperatures obtained over the probe height, the untapped condition proved a $3.00 \mathrm{~K}$ to $4.00 \mathrm{~K}$ lower temperature. Therefore, untapped conditions tended to decrease the overall chamber temperature [36].

Tapped conditions followed relatively the same trend whether additional heat was added or not. Conversely, the untapped conditions measured a rapid increase in the case with no additional heat, though a smoother transition was present for the heated case. Considering the increased, heated cases, the tapped condition attained a higher particles' bed level compared to the untapped condition. The tapped case showed a sudden increase in the bed height at the minimum fluidisation velocity region, whereas the untapped conditions increased as before. Higher bed heights were achieved with the tapped condition, whereas the untapped condition reaches the maximum bed height quicker at lower bed heights.

\section{CFD Modelling}

\subsection{Model Geometry, Mesh, and Mesh Independence}

The numerical model consisted of a simple 2D-rectangle with a uniform air inlet from the bottom as in figure 5a. The salient boundaries as shown in figure $5 \mathrm{a}$ are $\mathrm{A}$ - inlet, $\mathrm{B}$ - outlet, $\mathrm{C}$ - bed walls and D - heating element. A heating element was added at the bottom centre. The mesh, as shown in figure $5 \mathrm{~b}$, was predominantly quadrilateral cells with inflation on both outside edges and around the heating element. The inlet was set as a mass flow inlet. The outlet boundary was set as a pressure outlet at atmospheric pressure. The bed walls were set as no-slip and the heater wall was modelled at a constant temperature heated wall.

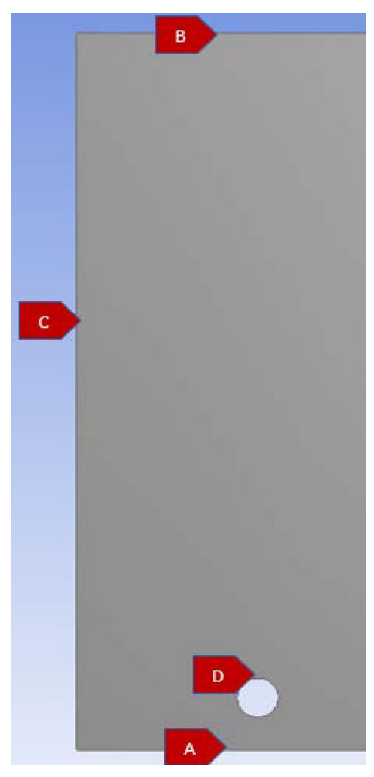

(a)

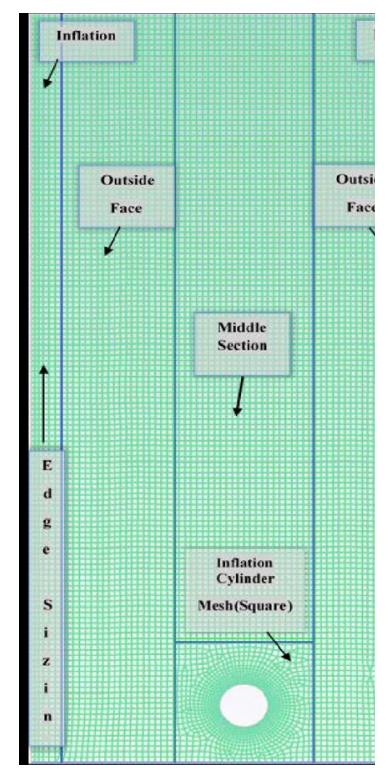

(b)
Figure 5 (a) Model geometry and salient Boundaries [36] (b) Computational mesh [36]

Three different mesh sizes $(2 \mathrm{~mm}, 1 \mathrm{~mm}, 0.5 \mathrm{~mm})$ were assessed through the Grid Conversion Index (GCI) approach [43] to ensure mesh independence. The GCI was calculated, as per table 3, for the mass weighted bed temperature and the 
Table 3 GCl-analysis for custom pressures and temperatures [36]

\begin{tabular}{|c|c|c|c|c|c|c|c|c|c|}
\hline Parameter & & & $\mathbf{f}_{1}$ & $\mathbf{f}_{2}$ & $\mathbf{f}_{3}$ & $\mathbf{f}_{\mathrm{h}=\mathbf{0}}$ & $\mathrm{GCI}_{2,3}(\%)$ & $\operatorname{GCI}_{1,2}(\%)$ & Asymptotic range \\
\hline $0.015 \mathrm{~m}$ & $T$ & $\mathrm{~K}$ & 312.00 & 310.99 & 309.33 & 313.57 & 1.04 & 0.63 & 1.01 \\
\hline $0.015 \mathrm{~m}$ & $\Delta P$ & $\mathrm{~Pa}$ & 363.71 & 354.67 & 347.10 & 308.12 & 16.76 & 19.11 & 1.05 \\
\hline $0.061 \mathrm{~m}$ & $T$ & $\mathrm{~K}$ & 312.00 & 311.00 & 308.02 & 312.51 & 0.61 & 0.20 & 1.01 \\
\hline $0.061 \mathrm{~m}$ & $\Delta P$ & $\mathrm{~Pa}$ & 1360.00 & 1274.40 & 1100.00 & 1442.52 & 19.10 & 7.58 & 1.24 \\
\hline
\end{tabular}

pressure drop. For both parameters the GCI was close to 1, indicating mesh independence on a base cell size of $0.5 \mathrm{~mm}$.

The Courant number was also used to validate convergence. A time-step of $0.0001 \mathrm{~s}$ was used to accommodate all residual variations to factors below $10^{-3}$ and energy below $10^{-6}$. Six flow rates were used to compare with the experimental values. The bed operated at Reynolds numbers below 2000, thus, the flow was modelled as laminar flow throughout the bed, ignoring the possibility of local regions of turbulence.

\subsection{Governing and Constitutional Equations}

The numerical method used throughout this study was the Finite Volume Method (FVM) based on the Navier Stokes (NS) equations [44]. The NS-equations consisted of three conservation equations: the conservation of mass, momentum, and energy [36]. Other equations acted as constitutional equations or as closure. These equations can be found in table 4.

The model ran with a multiphase Eulerian model consisting of a continuous air phase as the primary phase, and a dispersed fused alumina glass beads particle as the secondary phase. Implicit volume fraction, parameter formulation, and energy equations were used. The secondary phase properties were modelled through the partial differential equation and a granular temperature model. Lift forces were insignificant compared to the drag forces [45]. Also, as the fluidised bed at hand operates under laminar flow, the lift and virtual mass do not have a significant effect on the CFD-model [11], therefore, have not been added. The incompressible flow was modelled with a uniform velocity inlet and a constant static pressure outlet. The particle phase was patched to the cell zone to a minimum fluidised bed height of $0.6 \mathrm{~m}$. No slip-conditions were enforced at the walls.

In two-phase flow, the drag equation relates the two phases, which led to it being the main constitutive equation [45]. The drag equation depends on the particle shape, particle surface roughness, particle cohesiveness, and particle size distribution [46]. Thus, the drag model needs to be chosen specifically for the Geldart group B gas-solid fluidised bed. The Gidaspow model has proven itself to give a good comparison for dense fluidised beds $[47,48]$. It is based on a combination of the Wen and Yu model [46] which is based on the Richardson and Zaki (1954) model and the Ergun equation [46,49]. The Gidaspow has two fluid-solid exchange coefficients depending on the gas volume fraction. The granular bulk viscosity gives the resistance of the granular particles for compression and expansion [36].

In the plastic regime at low flow rates, particles are stacked densely with low shear [46]. The volume fraction of the particles are near the packing limit, thus, stresses are generated due to friction between the particles [46]. The Schaeffer equation is used to calculate the frictional viscosity. Friction viscosity determines the limit of the maximum packing in the granular flow regime where the solids' pressure decouples from the volume fraction [46]. For the Granular Temperature model, a partial differential equation is used. The transport equation is derived from the kinetic theory. The Syamlal et al. diffusion coefficient for granular energy is given by the drag modification factor [46]. The radial distribution function is critical in describing solid pressure which results from granular kinetic theory. The radial distribution acts as a correction factor that helps to modify the probability of collisions between the dense particles [44]. The volumetric rate of energy can be calculated using the temperature difference and interfacial area between phases. The heat exchange coefficient and the heat transfer coefficient [45] is calculated.

The simulations were investigated in two-fold, with the Gunn-model incorporated as the heat transfer through convection, as well as a Standard-model that does not incorporate the Gunn-equations but keeps all other equations the same.

\subsection{Model solver setup}

All models were run in 2D-double precision with the transient solver. A time-step of $0.0001 \mathrm{~s}$ accommodated all residual variations with $10^{-3}$ and energy below $10^{-6}$. All six flow rates converged in the iteration range between 10-25 iterations and proved to be most stable. The Lengau-cluster from the Centre of High-Performance Computing (CHPC) was used to simulate results essentially quicker through parallel computing techniques. Computational time was not reduced by the processing of the simulation but by the power of handling tasks simultaneously. This was achieved using Amdahl's law, which in effect reduces the time to finish the overall calculations. For each final simulation, 192 cores $(8 \times 24$ nodes $)$ were used to simulate the CFD-models. This significantly decreases the wall time compared to when only using a single computer $(1 \times 24$ nodes $)$. The wall times for simulations at $5 \mathrm{~s}$ for all the flow rates averaged at approximately 7 hours per simulation on the cluster, compared to a 5 day simulation time for a single computer operator.

Default settings were kept for the under-relaxation factors except for momentum of 0.2 [45] and granular temperature of 0.2 [45]. These residual limits were set to $<10^{-3}$ for all equations. The solution used higher order discretisation where possible to simulate realistic bubble shapes. Volume fraction did not perform well with higher-order discretisation

http://www.saimeche.org.za (open access) (C) SAIMechE All rights reserved. 
Table 4 Model equations

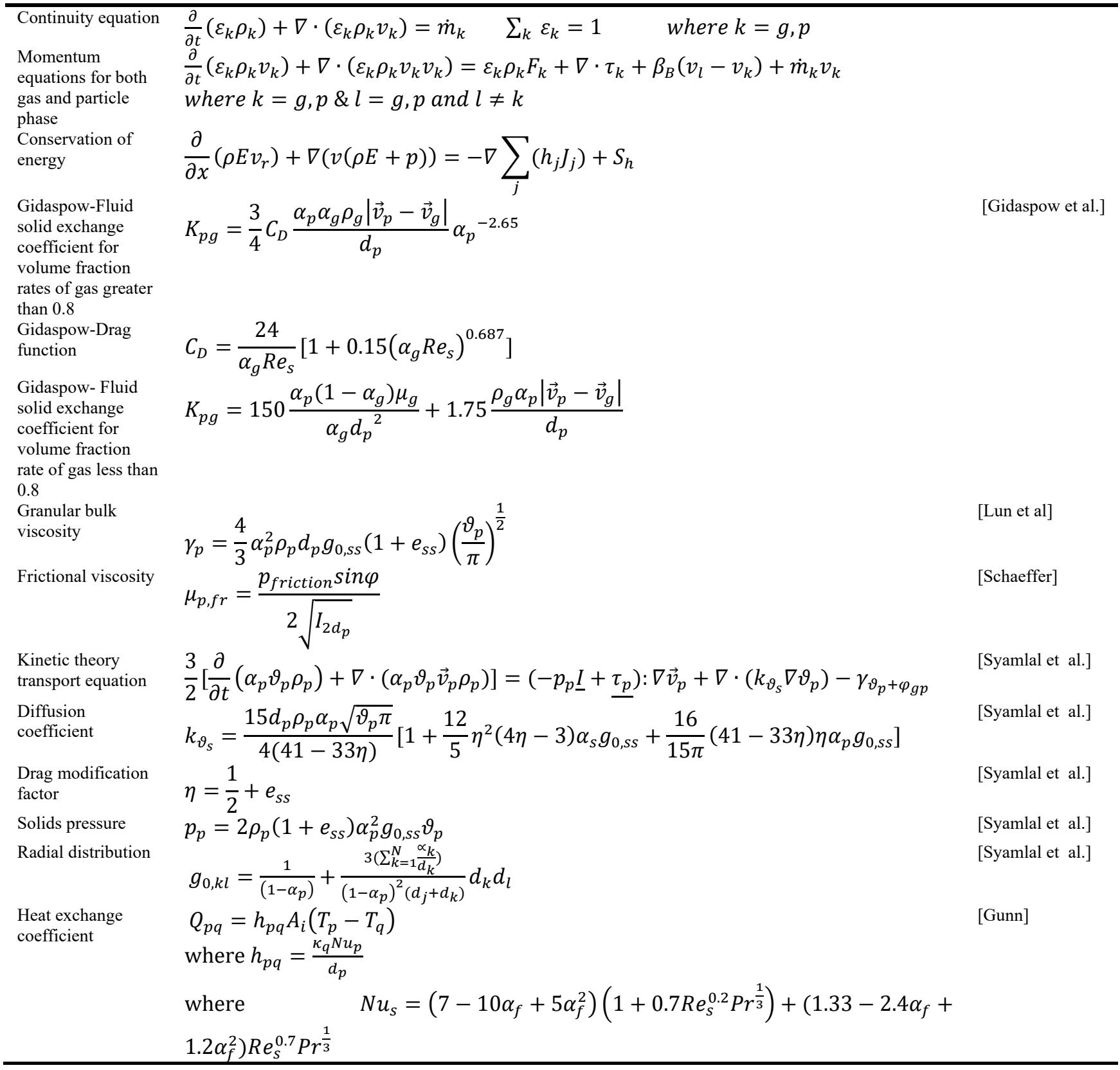

and resulted in numerical instability congruent with Bakker's [45] suggestion to use First-Order Upwind [47].

The phase coupled SIMPLE scheme was used with a Least Squares Cell-based gradient. The PRESTO! pressure interpolation scheme was used with momentum, granular temperature, and transient formulations as Second-Order Implicit. Volume fraction was kept as First-Order Upwind.

\section{Results and Discussion}

When comparing the experiments with the numerical simulations, the tapped heated case for increasing flow was used throughout the analysis, as it was the most comparable method. Six flow rates were compared to the results from the obtained CFD-models. These flow rates correlate to specific superficial velocities. In this paper simulation files would be referred to as their respective superficial velocity. The fixed- bed regime was obtained at the minimum superficial velocity of $0.046 \mathrm{~m} / \mathrm{s}$. Minimum fluidisation occurred at $0.071 \mathrm{~m} / \mathrm{s}$. The superficial velocity that correlates to the experimental values and was the closest to minimum fluidisation, was at $0.081 \mathrm{~m} / \mathrm{s}$. Only tiny bubbles developed, and slight motion was observed at the top of the particle bed surface level. A stable mixing of particles and gas was obtained at $0.115 \mathrm{~m} / \mathrm{s}$, resulting in bubbling fluidisation. This acts as the base reference and was used where no other explicit mention was given to a different flow rate. Other flow rates compared in the bubbling fluidisation regime were at $0.150 \mathrm{~m} / \mathrm{s}$, $0.162 \mathrm{~m} / \mathrm{s}$, and at maximum flow rate $0.196 \mathrm{~m} / \mathrm{s}$. The pressure drop, temperature and bed expansion were evaluated individually. 


\subsection{Pressure Drop Results}

Pressure drop was obtained across the chamber by subtracting the ambient pressure from the pressure obtained at the specific probe location. After $95 \mathrm{~mm}$, the probe was located above the particle bed surface level, resulting in a negligible pressure drop.

\subsubsection{Results with Relation to Probe Height}

During this study, $0.115 \mathrm{~m} / \mathrm{s}$ was modelled for $10 \mathrm{~s}$. Bubble size, coalescence, bubble motion and bubble frequency accounts for the motion of the fluid being dynamic, resulting in different localised pressure drops. Figures 6 and 7 show the comparison between the simulation and experiment for both models at a $10 \mathrm{~s}$ simulation time for left and right pressure probes respectively. The Gunn-model and Standardmodel showed similar pressure drops. At depths lower down in the fluidised chamber, the simulations slightly overpredicted the pressure drop, whereas above probe height of $50 \mathrm{~mm}$, the simulation was in good agreement with the experiment, with occasional underprediction. This can be due to more frictional tension obtained at the lower depths where more particles are present.

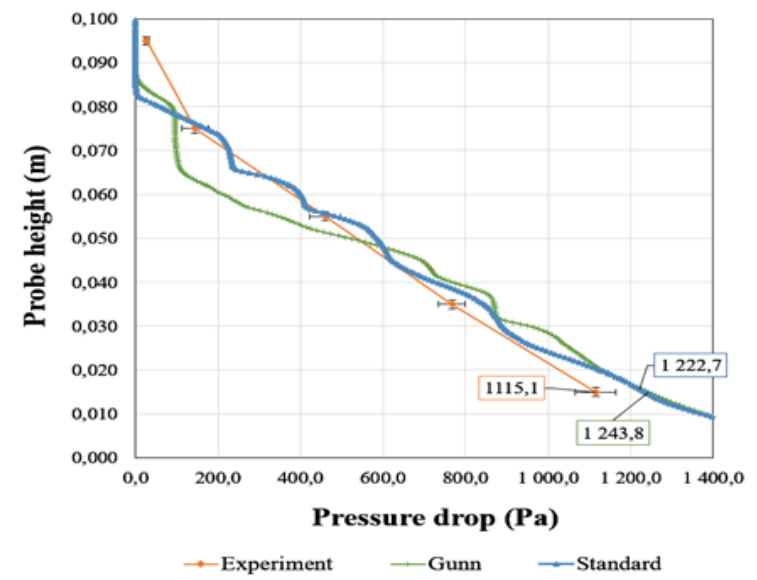

Figure 6 Comparison between CFD-model and experiment for pressure drop at $10 \mathrm{~s}$ simulation time for the left probe

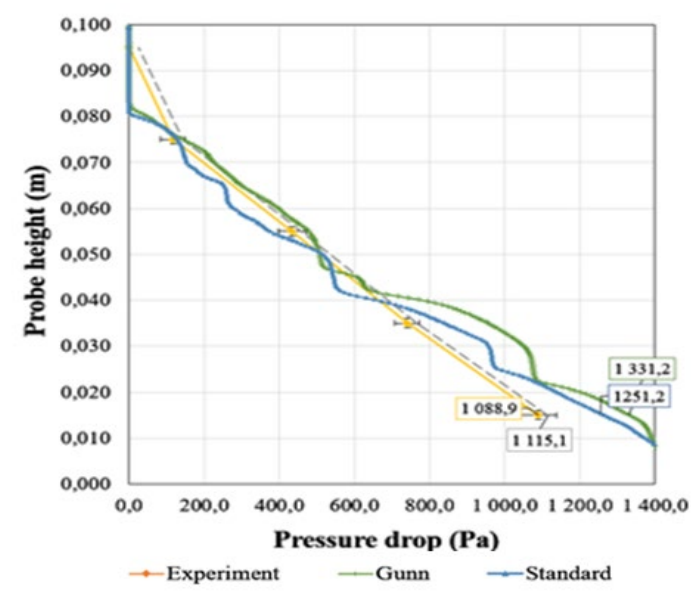

Figure 7 Comparison between CFD-model and experiment for pressure drop at $10 \mathrm{~s}$ simulation time for the right probe

These pressure drops also gave an indication of how the particles' surface bed level rose as it adjusted to the significant pressure drop between gas and the particle bed. A difference between experiment and simulation can be seen where experimental values vary linearly, whereas the simulations deviated from linearity as observed via fluctuations. When experimental values were taken, the bubbles rose rapidly, not remaining long in contact with the probe. When bubbles make contact with the pseudo-probe (used in the simulations), the pressure was captured at that exact time frame. However, in experiment, this phenomenon happens rapidly, and the pressure probe being limited not being able to instantaneously capture the exact pressure. This can account for the difference in trends.

The Gunn-model fluctuated between a $1.58 \%$ and $23.62 \%$ deviation, whereas the Standard-model fluctuated between a $13.45 \%$ to $74.94 \%$ deviation against the experiment up to a $10 \mathrm{~s}$ simulation time. The height differences were obtained lower in the bed where more particles were present and compressed. The Gunn-model indicated better agreement with the experiment, as expected. The CFD-models provided better agreement at higher probe height, leading to the neglection of taking surface tension into account. The CFD-model only achieved complete fluidisation after $5 \mathrm{~s}$ simulation time. The CFD-model compared very closely with previous research done by [26] who investigated a laminar gas-solid fluidised bed having a $200 \mathrm{~Pa}$ difference between experiment and CFD prediction. In this study, both models indicated at most a $163.3 \mathrm{~Pa}$ difference. Both are deemed as showing good agreement with experimental results for pressure drop.

\subsubsection{Results with Relation to Flow Rate}

For the following measurements, the flow rate was only calculated up to a simulation time of $5 \mathrm{~s}$ where the CFD-model reached complete fluidisation. From figure 8 , it can be seen that the superficial velocities below $0.115 \mathrm{~m} / \mathrm{s}$ proved stable data with fewer deviations to experimental data. These flows were not exposed to rapid hydrodynamics before. After a superficial velocity of $0.115 \mathrm{~m} / \mathrm{s}$, the CFD-model both overpredicted and underpredicted the experimental values dependent on the influence as a result of the presence of bubbles. It was, however, clear that the overall trend was a slight overprediction in pressure drop at all superficial velocities. The largest deviations were obtained at higher superficial velocities at $0.162 \mathrm{~m} / \mathrm{s}$ with a $34.0 \%$ and second largest at $0.150 \mathrm{~m} / \mathrm{s}$ with a deviation of $29.5 \%$. All other maximum deviations being less than $21.2 \%$ providing good agreement with the experimental results. At $0.046 \mathrm{~m} / \mathrm{s}$, the maximum deviation of the experimental value in relation to the CFD-model was $10.5 \%$. This was the lowest value recorded for all the compared flow rates. At $0.115 \mathrm{~m} / \mathrm{s}$, a maximum deviation of $17.3 \%$ was obtained. This shows acceptable agreement with the experiment.

\subsection{Temperature Results}

The temperatures presented in the results were calculated as a mass-weighted temperature of the particles and the gas. As particles and gas handle heat differently, the temperatures were calculated in the simulations by taking the temperature of each multiplied by their respective corresponding mass ratios (mass-weighted temperature). The initial conditions of the chamber particles and air were taken at room temperature

$$
\begin{array}{r}
R \& D \text { Journal of the South African Institution of Mechanical Engineering 2021, 37, 45-57 } \\
\text { http://dx.doi.org/10.17159/2309-8988/2021/v37a6 }
\end{array}
$$

http://www.saimeche.org.za (open access) (C) SAIMechE All rights reserved. 
with a heating element at instantaneous $373.15 \mathrm{~K}$ heat output. The initial chosen temperature also influenced the model output. An average room temperature of $300.15 \mathrm{~K}$ was used for all the models. Small initial changes could affect the values obtained.

\subsubsection{Results with Relation to Probe Height}

From figure 9, the Standard-model observes greater fluctuation compared to the Gunn-model. The Standardmodel took longer to reach steady fluidisation, whereas the 'new' incoming airstreams from the distributor and the 'older' airstreams already in the chamber mixed faster in the Gunn-model, accounting for less fluctuation in temperature at $10 \mathrm{~s}$. The temperature fluctuations were dependent on the cold air entering from the air distributor and convection induced from the heating element source. The difference between the particle bed and chamber air was not as significant in the Gunn-model, because more convection took place. The steady-state temperature was only reached at a $9 \mathrm{~s}$ simulation time. When the heat transfer coefficient was introduced by the Gunn-model, heat was transferred both from particle-to-particle and particle-to-air. More energy was recognised in the system with the addition of the heat transfer coefficient resulting in quicker full fluidisation. As the new air entered the chamber, the particles and gas mixed giving rise to a lower chamber temperature than before. The gas did not transfer the heat as efficiently as the particles and decreased the temperature.

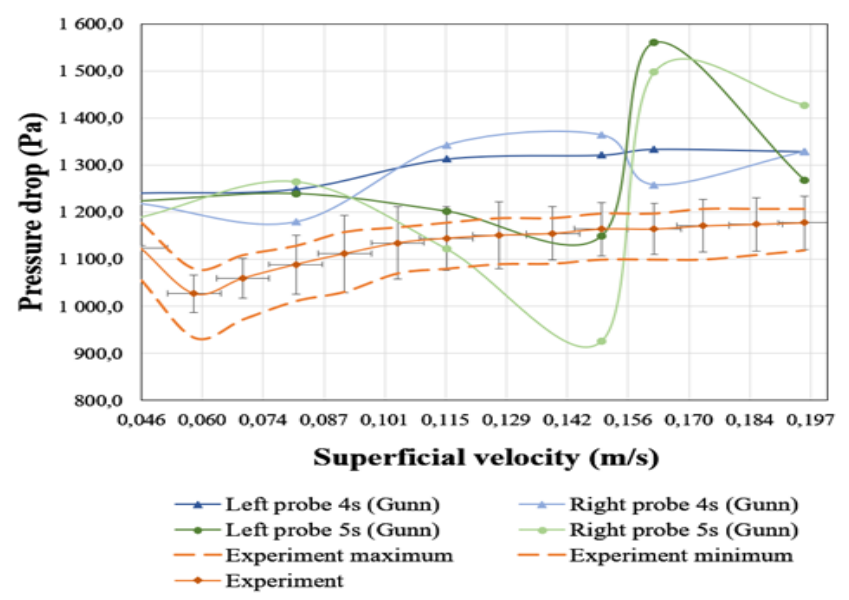

Figure 8 Comparison between CFD-model and experiment for pressure drop

The Standard-model showed overall the lowest temperature. The Gunn-model proved to be in better agreement with experimental results. The Gunn-model produced an overall higher temperature than the Standardmodel. In figure 9 both the error bounds for the untapped and tapped conditions are shown. Both the Standard-model and Gunn-model fall below the tapped boundaries; however, the Gunn-model reaches the untapped lower boundary. This indicates that even though the obtained temperatures are lower than the experiment, it is still in relatively close approximation. The average difference is approximately $6.00 \mathrm{~K}$ for the Gunn-model and $16.00 \mathrm{~K}$ for the Standardmodel. From these values it is clear that a heat exchange coefficient needs to be added in order to effectively capture the thermal dynamics in the bed.

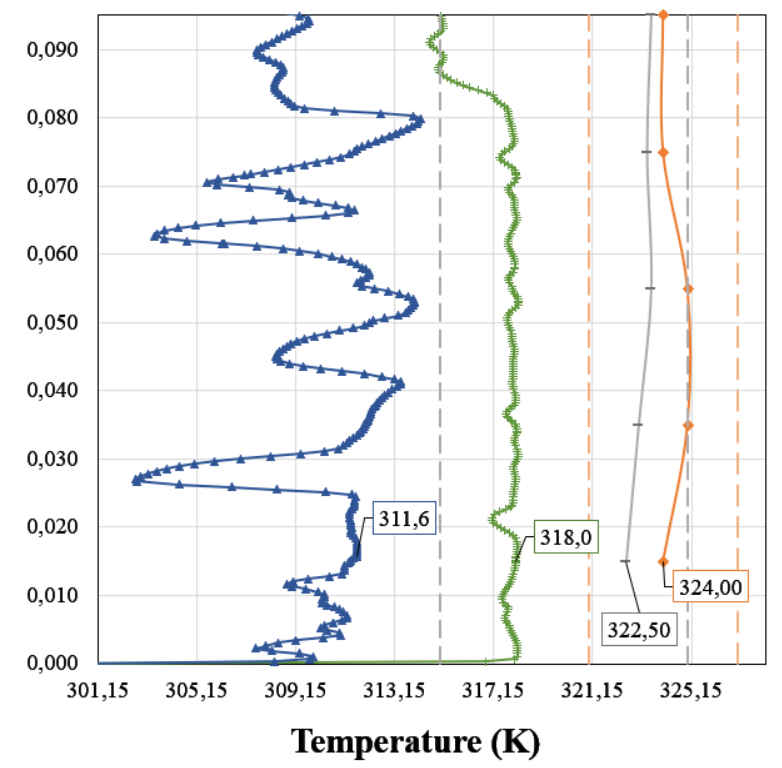

- Gunn
$\longrightarrow-$ Experiment Tapped
-- Experiment min- Tapped
-- Experiment min- Untapped

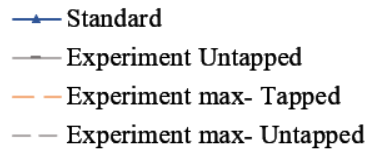

Figure 9 Comparison between CFD-model and experiment for temperature versus probe height at $10 \mathrm{~s}$.

\subsubsection{Results with Relation to Flow Rate}

A comparison was made between the tapped and untapped experimental conditions with the Gunn-model observation at $5 \mathrm{~s}$ simulation time for varying superficial velocities. A greater error bound was observed for the untapped condition than for the tapped condition.

At superficial velocities below $0.115 \mathrm{~m} / \mathrm{s}$, higher fluctuations were observed in temperatures whereas, after $0.115 \mathrm{~m} / \mathrm{s}$, the Gunn-model again reached the lower bound of the error bound for untapped conditions very closely. It falls $3.00 \mathrm{~K}$ short of reaching the error bound for the tapped conditions. As values in the tapped bounds were desired, the overall observation was supported by observation in figure 10 as an underprediction of chamber temperature. The heat transfer coefficient could have influenced the temperature recorded, including initial ambient and heating element temperatures. The suggestion was made to model a gas-solid fluidised bed with heat transfer as a 3D-model instead.

In the CFD-model, the heat output was stable at a constant rate of $373.15 \mathrm{~K}$, whereas during the experiments the output fluctuated between $364.15 \mathrm{~K}$ to $383.15 \mathrm{~K}$. These "bursts" of energy output could be the reason for a marginal higher temperature difference against the CFD-model. Low ambient temperature settings during CFD-modelling might also have an influence. Another influence on the temperature output on the model could have been the result of the heat transfer coefficient used. It was therefore advised that future studies should consider the specific heat transfer coefficient being used in their evaluation criteria.

The argument was made that a Lagrangian model would be able to capture temperature and heat transfer dynamics 
more sufficiently than a Eulerian model improving heat transport captured between particles-particle interactions. It was argued that more influence on the heat transfer through the bed could be expected for modelling the flow as a 3Dmodel instead of directly reverting to the Lagrangian model. During the 2D-model only the circumference of the circular heating element dissipated heat whereas for a 3D-model the surface of the whole cylindrical heating element would assist in transferring heat. The 3D-model would this consist of a region with greater heat output in all directions.

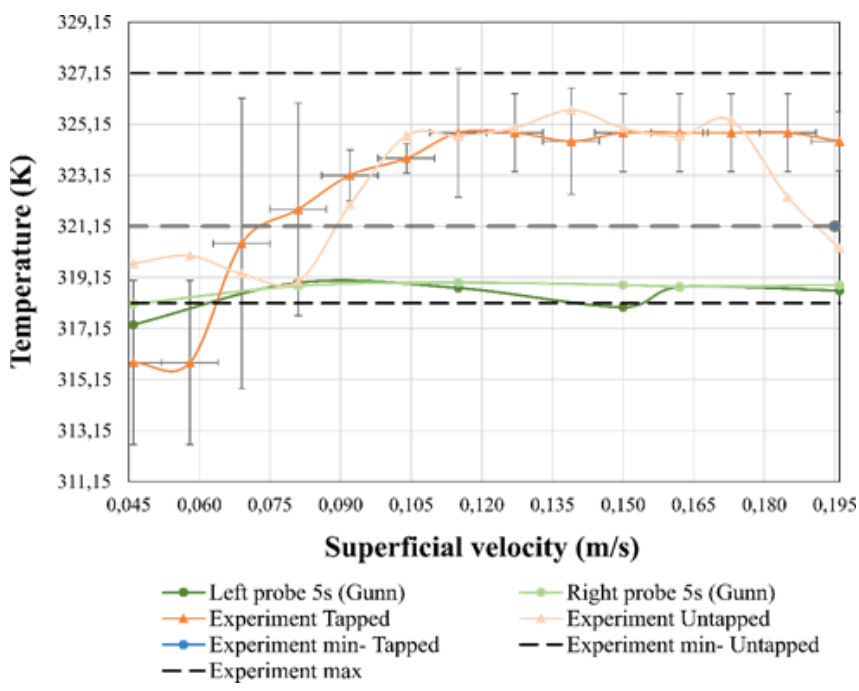

Figure 10 Comparison between CFD-model and experiment for temperature versus flow rate

\subsection{Bed Expansion Results}

Bed expansion provides a degree of momentum coupling between the phases. A higher bed expansion signifies greater significance for overall drag forces experienced by the particles [25].

\subsubsection{Results with Relation to Flow Rate}

Bed heights were dependent on the amount of air entering the particle bed, bubbles pushed the particles up, which occupied more space. The bed expansion was overpredicted where the additional bed expansion could gather up between 2.3 to $4.5 \%$ of the overall chamber volume. For the superficial velocities at and below the minimum fluidisation velocity, the bed height was in good agreement with the experiment ranging within the standard deviation error bound. This can be observed in figure 11. The pressure drops at the highest superficial velocity indicated a $15.7 \%$ overprediction. In the bubbling regime, the bed expansion rose exponentially and increased in overprediction. Overprediction could indicate an overprediction in voidages for different flow regimes. Overprediction of bed heights further gave an indication of over-prediction in bubble frequency. This was in line with the overprediction of the pressure drop for varying superficial velocities. The bed heights correlates to the voidages introduced into the system. Thus, overprediction of the bed height indicates an overprediction of voidage in size or frequency.

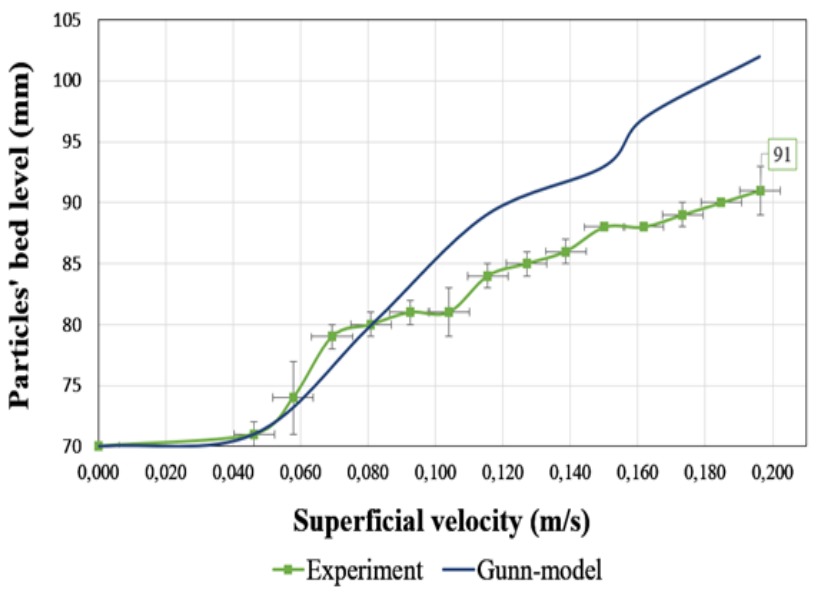

Figure 11 Comparison between CFD-model and experiment for temperature versus bed heights

\subsubsection{Results of Flow Regime}

Each flow rate started with a voidage of 0.6 after which air was introduced to a stationary bed of particles for the specified flow rates (correlating with the superficial velocities). This corresponded to the voidage obtained when no flow rate was induced. Figure 12 shows the gas to solid fraction of the fluidised bed at a $5 \mathrm{~s}$ simulation time for all six superficial velocities. At $0.0461 \mathrm{~m} / \mathrm{s}$ no visible bubbles are present indicating a fixed bed. At $0.081 \mathrm{~m} / \mathrm{s}$ only tiny bubbles are present with slight motion at the top where bubbles develop, corresponding to the minimum fluidisation velocity region. Flow rates at $0.115 \mathrm{~m} / \mathrm{s}$ to $0.196 \mathrm{~m} / \mathrm{s}$ indicates larger and more prominent voidages with higher frequency of bubble formation. The greater the presence of larger bubbles, due to increased superficial velocities, the greater the deviation between experiment and CFD-model. Similarly, these differences can be observed in figure 13 which is represented by images from experiment with the corresponding flow rates and time frames. Figures 12 and 13 show similar trends with slightly less bubble formation in figure 13.

Figure 14 shows the flow at a superficial velocity of $0.115 \mathrm{~m} / \mathrm{s}$ at $1 \mathrm{~s}$ to $10 \mathrm{~s}$. In both figures the bubble behaviour can be observed as well as how it influences the bed expansion. The CFD-models showed similarities in bubble shape to experimental observation. The specific bubble size was not determined. It was evident that the model overpredicted the number of bubbles in the chamber. Every simulation for individual flow rates needed to surmount the initial surface tension of the bed. This could have resulted in a higher bed expansion as higher superficial velocities gave rise to elevated bed heights, accounting for overprediction on these. The Algebraic Interfacial Area Density (AIAD) model, as defined by [50], where the bubble phase can be included as a 'virtual' third phase with mass transfer mechanisms, may be worth exploring for better resolution of the bubbles. 


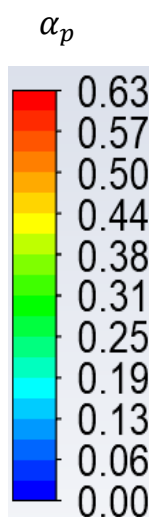

$0.0461(\mathrm{~m} / \mathrm{s})$

$0.081(\mathrm{~m} / \mathrm{s})$

$0.115(\mathrm{~m} / \mathrm{s})$
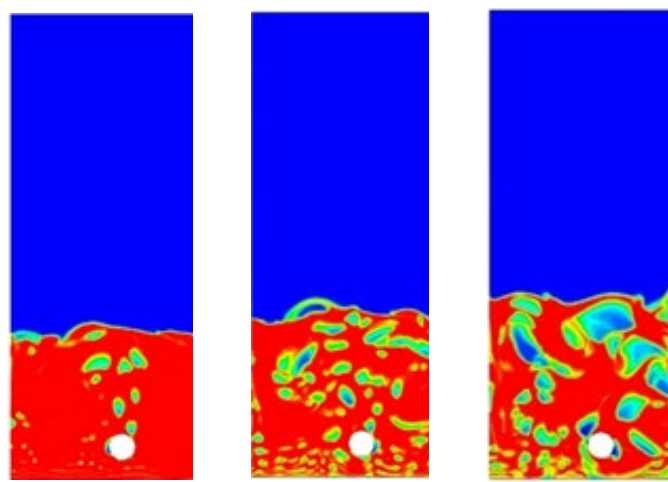

$0.150(\mathrm{~m} / \mathrm{s})$

$0.162(\mathrm{~m} / \mathrm{s})$

$0.196(\mathrm{~m} / \mathrm{s})$
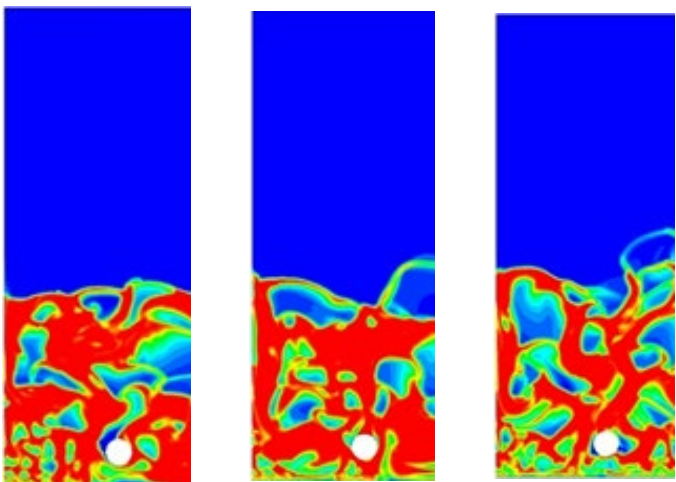

Figure 12 Contours coloured by particle volume fraction $\left(\alpha_{p}\right)$ for varying superficial velocities at $5 \mathrm{~s}$ of flow time

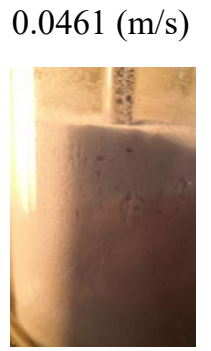

$0.081(\mathrm{~m} / \mathrm{s})$

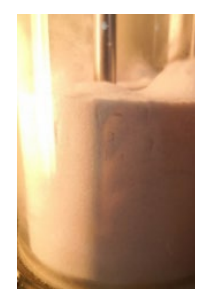

$0.115(\mathrm{~m} / \mathrm{s})$

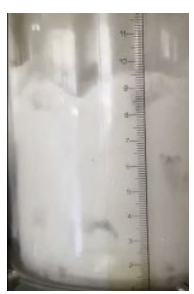

$0.150(\mathrm{~m} / \mathrm{s})$

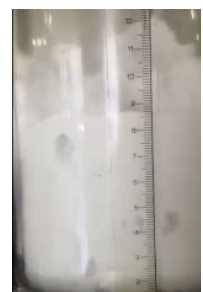

$0.162(\mathrm{~m} / \mathrm{s})$

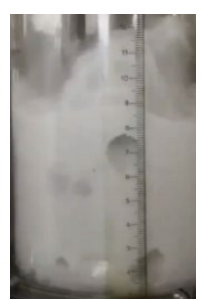

$0.196(\mathrm{~m} / \mathrm{s})$

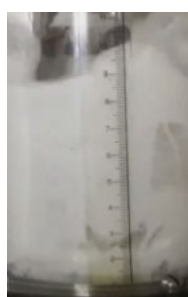

Figure 13 Experimental results at varying flow rates at $5 \mathrm{~s}$ of flow time

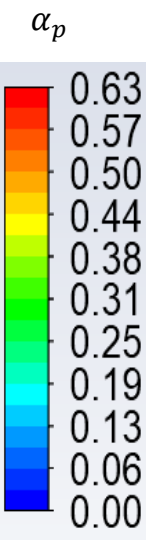

$1(\mathrm{~s})$

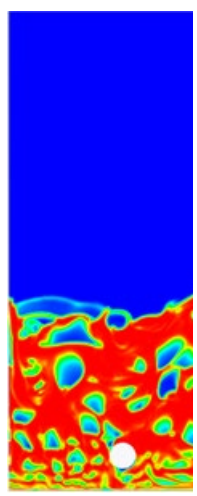

$2(\mathrm{~s})$

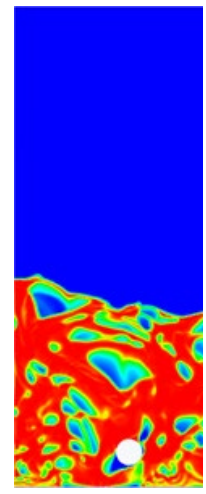

$3(\mathrm{~s})$

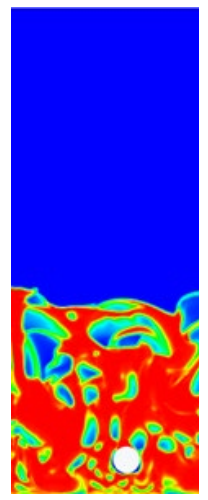

$5(s)$

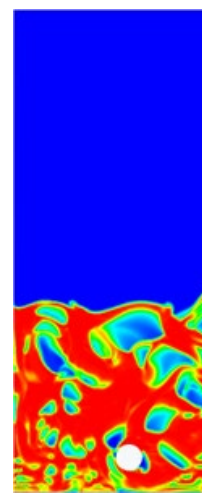

$8(\mathrm{~s})$

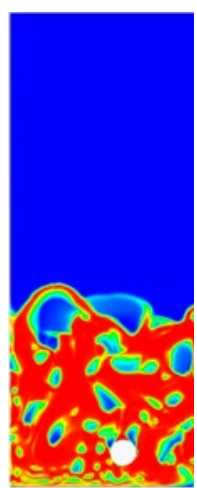

$10(\mathrm{~s})$

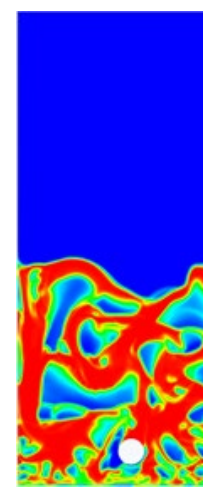

Figure 14 Time evolution of contours coloured by particle volume fraction $\left(\alpha_{p}\right)$ at superficial velocity $0.115 \mathrm{~m} / \mathrm{s}$

\section{Conclusion}

The primary objective of the study was to determine whether the Eulerian-models adequately predict the chamber pressure drop, temperature, and bed height of a gas-solid fluidised bed. The predictions were assessed under various flow-regimes, namely the fixed-bed, smooth, bubbling fluidisation, and the maximum fluidisation regimes. For values taken across the bed in a vertical direction at a superficial velocity of $0.115 \mathrm{~m} / \mathrm{s}$, the Eulerian-model was in good agreement with experiment within a range of $21 \%$ overprediction. The bed height was in line with the overprediction of the pressure drop trends. The overpredicted bed expansion accounted for less than $4.5 \%$ of the total volume of the chamber. Overprediction of the bed expansion stems from the overprediction of voidages (bubbles) in the fluidised bed. The Eulerian-model underpredicted the chamber temperature by $6.00 \mathrm{~K}$ while falling $2.00 \mathrm{~K}$ short of being in the error bound.
At a probe height of $15 \mathrm{~mm}$, the Eulerian-model provided an underprediction against the experiment results within a $7.00 \mathrm{~K}$ range across a superficial velocity range between $0.0461 \mathrm{~m} / \mathrm{s}$ to $0.196 \mathrm{~m} / \mathrm{s}$. The overall temperature tests concluded an underprediction of chamber temperature trends.

The proposed model provided good agreement with experiment. However, overprediction or underprediction is observed, particularly at flow rates beyond the minimum fluidisation velocity. Furthermore, the model overpredicted the size of the bubbles.

Thus, further work needs to be carried out to develop a more versatile/robust model that provides greater accuracy beyond the minimum fluidisation velocity. Future work will also focus on the application of the AIAD model for better resolution of the bubbles. In addition, Future studies can focus on how the particle size distribution and particle shapes influence simulations and how it compares with this study.

http://www.saimeche.org.za (open access) (C) SAIMechE All rights reserved. 
Research can also focus on defining the bubble-bubble interaction.

\section{Acknowledgements}

The authors acknowledge the National Research Foundation (NRF) for their financial assistant and The Centre for High Performance Computing (CHPC) for the use of the cluster. Opinions expressed are wholly the author's own opinions and not attributed by either the NRF or CHPC.

\section{References}

1. S. K. Majumder. Lecture: Introduction to Fluidization Engineering, Department of Chemical Engineering, Indian Institute of Technology, 2018, https://onlinecourses.nptel.ac.in/noc21 ch41/preview.

2. D. M. Parikh. How to Optimize Fluid Bed Processing Technology. Academic Press, London, 2017.

3. General Kinematics. (n.d.). Fluid Bed Dryer Uses and Applications. URL

https://www.generalkinematics.com/blog/fluid-beddryer-uses-applications/.

4. S. K. Majumder. Lecture: Bubbling Fluidization Part 1: Bubbling Characterization, Department of Chemical Engineering, Indian Institute of Technology, 2018, https://onlinecourses.nptel.ac.in/noc21 ch41/preview.

5. D. Geldart. Types of gas fluidization. Powder Technology, 7(5):285-292, 1973.

6. S. K. Majumder. Lecture: Flow regime and its map: Gas-solid Fluidization, Department of Chemical Engineering, Indian Institute of Technology, 2018, https://onlinecourses.nptel.ac.in/noc21 ch41/preview.

7. A. Bakker. Lecture: Applied Computational Fluid Dynamics: Lecture 2 - Flow Fields, Darthmouth University, 2008.

http://www.bakker.org/dartmouth06/engs150/02post.pdf.

8. J. T. Cornelissen, F. Taghipour, R. Escudié, N. Ellis and J. R. Grace. CFD modelling of a liquid-solid fluidized bed. Chemical Engineering Science, 62(22):6334-6348, 2007.

9. S. K. Majumder. Lecture: Minimum Fluidization Velocity: fluid-solid System, Department of Chemical Engineering, Indian Institute of Technology, 2018, https://onlinecourses.nptel.ac.in/noc 21 ch41/preview.

10. J. Schoombie. A comparison of ANSYS Fluent and STAR-CCM+ simulations for a tangent ogive slender body with a structured mesh at incompressible flow conditions. Council for Scientific and Industrial Research (CSIR), 2013. URL https://researchspace.csir.co.za/dspace/bitstream/handle /10204/10010/Schoombie_19954_2017.pdf?sequence= 1 \&isAllowed $=\mathrm{y}$.

11. D. Gidaspow. Multiphase Flow and Fluidization: Continuum and Kinetic Theory Descriptions. Academic Press, London, 1994.

12. D. E. Guevara. Bed Height and Material Density Effects on Fluidized Bed Hydrodynamics. Master's thesis, Iowa State University, USA, 2010.

13. S. K. Majumder. Lecture: Heat transfer Characteristics, Department of Chemical Engineering, Indian Insti- tute of Technology, 2018,

https://onlinecourses.nptel.ac.in/noc21_ch41/preview.

14. J. Aronsson, D. Pallarès, M. Rydén, and A. Lyngfelt. Increasing gas-solids mass transfer in fluidized beds by application of confined fluidization - A feasibility study. Applied Sciences, 9(4):634, 2019.

15. C. Cooper and C. M. Hall. Oceania: A Tourism Handbook. Channel View Publications, Clevedon, 2005.

16. C. Dechsiri. Particle Transport in Fluidized Beds: Experiments and Stochastic Models. PhD thesis, University of Groningen, 2004.

17. R. P. Chhabra and J. F. Richardson. Non-Newtonian Flow in the Process Industries: Fundamentals and Engineering Applications. Butterworth-Heinemann, Oxford, 1999.

18. Z. Qinghong, W. Shuyan, L. Huilin, L. Guodong, W. Shuai, and Z. Guangbo. A coupled Eulerian fluid phaseEulerian solids phase-Lagrangian discrete particles hybrid model applied to gas-solids bubbling fluidized beds. Powder Technology, 315:385-397, 2017.

19. J. F. Price. Lagrangian and Eulerian Representations of Fluid Flow Kinematics and the Equations of Motion, MIT OpenCourseWare, 2006. URL

https://www.whoi.edu/science/PO/people/jprice/class/E Lreps.pdf.

20. M. Upadhyay, H. C. Park, J. G. Hwang, H. S. Choi, H.N Jang and Y.-C. Seo. Computational particle-fluid dynamics simulation of gas-solid flow in a circulating fluidized bed with air or $\mathrm{O} 2 / \mathrm{CO} 2$ as fluidizing gas. Powder Technology, 318:350-362, 2017.

21. D. Hirche, F. Birkholz, and O. Hinrichsen. A hybrid Eulerian-Eulerian-Lagrangian model for gas-solid simulations. Chemical Engineering Journal, 377:119743, 2019.

22. J. Le Lee and E. W. C. Lim. Comparisons of EulerianEulerian and CFD-DEM simulations of mixing behaviors in bubbling fluidized beds. Powder Technology, 318:193-205, 2017.

23. J. Chang, Z. Wu, X. Wang and W. Liu. Two- and threedimensional hydrodynamic modeling of a pseudo-2D turbulent fluidized bed with Geldart B particle. Powder Technology, 351:159-168, 2019.

24. Q. Zhou and J. Wang. CFD study of mixing and segregation in CFB risers: Extension of EMMS drag model to binary gas-solid flow. Chemical Engineering Science, 122:637-651, 2015.

25. R. Khezri, W. A. Wan Ab Karim Ghani, S. Masoudi Soltani, D. R. Awang Biak, R. Yunus, K. Silas, M. Shahbaz and S. Rezaei Motlagh. Computational fluid dynamics simulation of gas-solid hydrodynamics in a bubbling fluidized-bed reactor: Effects of air distributor, viscous and drag models. Processes, 7(8):524, 2019.

26. M. Deza, F. Battaglia and T. J. Heindel. Approximating a Three-Dimensional Fluidized Bed with TwoDimensional Simulations. In Proceedings of ASME International Mechanical Engineering Congress and Exposition, 387-394, 2008.

http://www.saimeche.org.za (open access) (C) SAIMechE All rights reserved. 
27. S. Kumar. CFD Validation for forces on immersed tubes in fluidized bed. Journal of Chemical Engineering \& Process Technology. 7(4):311, 2016.

28. I. Hulme, E. Clavelle, L. Van der Lee and A. Kantzas. CFD modeling and validation of bubble properties for a bubbling fluidized bed. Industrial \& Engineering Chemistry Research, 44(12):4254-4266, 2005.

29. E. Doroodchi, K. P. Galvin and D. Fletcher. The influence of inclined plates on expansion behaviour of solid suspensions in a liquid fluidised bed-a computational fluid dynamics study. Powder Technology, 160(1):20-26, 2005.

30. O. Molerus. Fluid mechanics and heat transfer in fluidized beds. KONA Powder and Particle Journal, 18:121-130, 2000.

31. Q. F. Hou, Z. Y. Zhou and A. B. Yu. Gas-solid flow and heat transfer in fluidized beds with tubes: Effects of material properties and tube array settings. Powder Technology, 296:59-71, 2016.

32. M. M. Shah. General correlation for maximum heat transfer to surfaces submerged in gas-fluidized beds. Chemical Engineering Science, 185:127-140, 2018.

33. H. Bodhanwalla and M. Ramachandran. Parameters affecting the fluidized bed performance: A review. REST Journal on Emerging Trends in Modelling and Manufacturing, 3(1):17-21, 2017.

34. J. W. Slater. Overview of CFD Verification \& Validation. NASA, 2008, URL

https://www.grc.nasa.gov/WWW/wind/valid/tutorial/ov erview.html.

35. S. Benzarti, H. Mhiri, H. Bourno and R. Occelli, Simulation of gas-solid turbulent fluidized bed hydrodynamic. In the Proceedings of the 14th International Conference on Fluidization - From Fundamentals to Products, 2013.

36. A. Potgieter. Modelling of a Heated Gas-solid Fluidised Bed using Eulerian Based Models. Master's thesis, University of Johannesburg, South Africa, 2020.

37. Y. Behjat, S. Shahhosseini and S. H. Hashemabadi. CFD modeling of hydrodynamic and heat transfer in fluidized bed reactors. International Communications in Heat and Mass Transfer, 35(3):357-368, 2008.

38. S. Bellan, N. Gokon, K. Matsubara, H. S. Cho and T. Kodama. Numerical and experimental study on granular flow and heat transfer characteristics of directlyirradiated fluidized bed reactor for solar gasification. International Journal of Hydrogen Energy, 43(34):16443-16457, 2018.

39. S. Bellan, K. Matsubara, H.S. Cho, N. Gokon and T. Kodama, A CFD-DEM study of hydrodynamics with heat transfer in a gas-solid fluidized bed reactor for solar thermal applications. International Journal of Heat and Mass Transfer, 116, 377-392, 2018.

40. J. Li, R. K. Agarwal and B. Yang. Two-Dimensional Computational Fluid Dynamics Simulation of Heat Removal in Fluidized Bed Methanation Reactors from Coke Oven Gas Using Immersed Horizontal Tubes. Industrial and Engineering Chemistry Research, 59(2):981-991, 2019.

41. H. Luo, H. Wu, W. Lin and K. Dam-Johansen. A heat transfer corrected isothermal model for CFD modeling of biomass devolatilization in fluidized beds. In Proceedings of $23^{\text {rd }}$ International Conference on Fluidized Bed Conversion, Seoul, Republic of Korea, 2018.

42. L. Mu, K. A. Buist, J. A. M. Kuipers and N.G. Deen. Hydrodynamic and heat transfer study of a fluidized bed by discrete particle simulations. Processes, $8(4): 463,2020$

43. P. J. Roache. Perspective: A method for uniform reporting of grid refinement studies. Journal of Fluids Engineering, 116(3):405-413, 1994.

44. S. Ramathan, Lecture: Fixed bed and fluidized bed, Indian Institute of Technology - Madras, 2005. http://www.che.iitm.ac.in/ srinivar

45. A. Bakker. Lecture: Applied Computational Fluid Dynamics: Lecture 14 -Multiphase Flows, Darthmouth University, 2008.

http://www.bakker.org/dartmouth06/engs150/14multi.pdf.

46. ANSYS Inc. ANSYS FLUENT Theory Guide Release 2020R1, 2020.

47. L. Huilin, D. Gidaspow, J. Bouillard and L. Wentie. Hydrodynamic simulation of gas-solid flow in a riser using kinetic theory of granular flow. Chemical Engineering Journal, 95(1-3):1-13, 2003.

48. C. Y. Wen and Y. H. Yu. Mechanics of fluidization. Chemical Engineering Progress Symposium Series, 62:100-111, 1966.

49. S. Ergun. Fluid flow through packed columns. Chemical Engineering Progress, 48:89-94, 1952.

50. G. Montoya. Development and Validation of Advanced Theoretical Modeling for Churn-Turbulent Flows and Subsequent Transitions. PhD thesis, HelmholtzZentrum Dresden, Germany, 2015.

http://www.saimeche.org.za (open access) C SAIMechE All rights reserved. 